\title{
Antimicrobial resistance patterns and genotypic diversity between clinical and water systems isolates of Pseudomonas aeruginosa in Cali, Colombia
}

\author{
Chávez, M. ${ }^{1}$, Cabezas, A.F. ${ }^{2}$, Ferauds, M. ${ }^{3}$, Castillo, J.E. ${ }^{4}$ and Caicedo, L.D. ${ }^{5}$ \\ ${ }^{1}$ Professor Department of Biomedical Sciences, Faculty of Health, Universidad Santiago de Cali, \\ Campus Pampalinda, Calle 5 \# 62-00, Colombia \\ ${ }^{2}$ Medicine Program, Faculty of Health, Universidad Santiago de Cali \\ ${ }^{3}$ Medicine Program, Faculty of Health, Universidad Santiago de Cali \\ ${ }^{4}$ Professor Department of Natural Sciences, Exact and Statistics, Faculty of Basic Sciences, \\ Universidad Santiago de Cali, Campus Pampalinda, Calle 5 \# 62-00, Colombia \\ ${ }^{5}$ Professor Department of Natural Sciences, Exact and Statistics, Faculty of Basic Sciences, \\ Universidad Santiago de Cali, Campus Pampalinda, Calle 5 \# 62-00, Colombia \\ *Corresponding author e-mail: moikchavez@gmail.com \\ Received 1 April 2020; received in revised form 2 June 2020; accepted 10 June 2020
}

\begin{abstract}
Pseudomonas aeruginosa is considered an opportunistic pathogen, causing a wide variety of infections in compromised hosts, also frequently develops multi-resistance to antibiotics and can colonize various habitats, including water systems. The main aim of this study was to investigate antibiotics susceptibility pattern, genotypic diversity and detection of resistence genes in $P$. aeruginosa isolates from clinical and aquatic environment sources. Of the $220 P$. aeruginosa isolates examined, 48 were clinical isolates and 172 isolates from wastewater and freshwater. Susceptibility to eight antimicrobial agents was carried out by disk diffusion method. Clinical and environmental isolates were screened for the presence of the genes encoding $b l a_{\mathrm{KPC}-2}, b l a_{\mathrm{CTX}-\mathrm{M}-9}, b l a_{\mathrm{PER}-1}, b l a_{\mathrm{OXA}-10}, b l a_{\mathrm{IMP}-1}, b l a_{\mathrm{VIM}-2}$ and $b l a_{\mathrm{ampC}}$ by polymerase chain reaction (PCR). Isolates were examined with PCR-SSCP analysis of partial DNAr $16 \mathrm{~S}$ sequence. Isolates were mainly resistant to cefoxitin. Multidrug-resistant $P$. aeruginosa (MDRPA) strains were found in $70 \%$ and $90.3 \%$ of the clinical and environmental isolates, respectively. The prevalence rates of â-lactamase genes were recorded $\left(b l a_{\mathrm{KPC}-2}\right.$ $41.3 \%, b l a_{\mathrm{VIM}-2} 36.8 \%, b l a_{\mathrm{IMP}-1} 13.6 \%, b l a_{\mathrm{CTX}-\mathrm{M}-9} 10.9 \%$ and $b l a_{\mathrm{ampC}} 10.5 \%$,). The PCR-SSCP analysis showed three conformational patterns. All clinical isolates and most environmental isolates were grouped into a single cluster. In this study, we found that $P$. aeruginosa strains recovered from city water systems must be considered potential reservoir for ESBL genes, especially blaKPC-2 and blaVIM-2.
\end{abstract}

\section{INTRODUCTION}

Pseudomonas aeruginosa is an opportunistic pathogen that has been emerging as a primary source of nosocomial infections, and can cause urinary and respiratory tract infections, soft tissue infections, endocarditis, and a variety of systemic infections, particularly in burned patients, with cancer, cystic fibrosis, or compromised immune systems (Giamarellou, 2002; Inglis et al., 2010; Luna et al., 2013; Allen et al., 2014).
The treatment is often complicated, because this microorganism has intrinsic multidrug resistance and several strains have acquired resistance genes to a wide variety of antimicrobials, including to most commercially available $\beta$-lactams (Lambert, 2002, Rodríguez et al., 2009; Jeannot et al., 2013; Magiorakos et al., 2012). Resistance to carbapenems is produced especially by the production of metallo- $\beta$-lactamases and serine enzymes (Lambert, 2002; Rodríguez et al., 2009; Jeannot et al., 2013). 
In recent years the circulation of strains has increased resistant to carbapebemes and to other antimicrobials, has led to the emergence of multidrug-resistant $P$. aeruginosa (MDRPA).

$P$. aeruginosa can grow in many environments, it is found in water, soil, sewage, animal faeces, on vegetation and the human body and has a great capacity to adapt to the environment, survive extremes which includes temperatures ranging from $4^{\circ} \mathrm{C}$ to $43^{\circ} \mathrm{C}$, and weak ion concentrations, among others (Wu et al., 2012; Lalancette et al., 2017).

Several Studies on the molecular epidemiology and population structure of Gram-negative bacteria have shown that incidence of the bacterium in the aquatic environment has increased as a consequence of the large-scale use of antibiotics (Baquero, et al., 2008; Scotta et al., 2011; Vaz-Moreira et al., 2012; Akinpelu et al., 2014). P. aeruginosa often is found in natural waters such as lakes and rivers in concentrations of 10/100 mL to >1 000/100 Ml (Vaz-Moreira et al., 2012).

Some studies indicate that the environmental reservoirs of the $P$. aeruginosa can be a source of infection (Yang et al., 2009; Scotta et al., 2011; Breathnach et al., 2012; Decker \& Palmore 2013; Cortes et al., 2013), thus, healthcare-associated infections can also be linked to contaminated water systems, especially among immunocompromised and severely ill patients (Yang et al., 2009; Breathnach et al., 2012; Decker \& Palmore, 2013).

In Colombia, studies have focused on the characterization of MDRPA in clinical isolates from patients with $P$. aeruginosa infections (Crespo et al., 2004; Cortes et al., 2013; Vanegas et al., 2014; Correa et al., 2015), but little information is available on the distribution in the environment, especially in water systems. In this study, we evaluated the antibiotic resistance patterns of $P$. aeruginosa isolated from clinical samples of patients with nosocomial infection and water systems of the city of Cali, focusing on the identification of highrisk clones and of $\beta$-lactam resistance genes.

\section{MATERIAL AND METHODS}

Study area and sampling. The artificial waters samples were collected from the wastewater treatment plant "Cañaveralejo PTAR-C" (sampling site A), a rainwater channel (B), that receives discharges of domestic wastewater, and so-called "Canal Intersector (CVC) Sur" (sampling site C), that receives the waste load from the southeast of the Cali city (geographical coordinates: $3^{\circ} 27^{\prime} 00$ "N $76^{\circ} 32^{\prime} 00^{\prime} \mathrm{W}$, in southwestern Colombia). Similarly, the freshwater samples were collected from Cauca River at the height of the Puerto Mallarino plant (D) and Melendez River (E) at the points indicated on the map (Figure 1). The samples were obtained in two periods: during the dry season (January) and during the wet season (May) of 2018.

Wastewater effluent and receiving river water samples were collected from point collection in triplicate in $500 \mathrm{ml}$ brown glass bottles protected with aluminum seal and / or Teflon cap, completely filled and kept at $4^{\circ} \mathrm{C}$ in an icebox containing ice during the transportation to the laboratory and processed immediately for the enumeration of bacteria.

In the case of clinical samples, 48 isolates were obtained from patients who were in the Intensive Care Unit (ICU) of the University Hospital San Juan de Dios in the city of Cali with invasive infection by $P$. aeruginosa between the months of January and May 2018. This invasive infection is defined as the isolation of bacteria from a normally sterile site in a patient with clinical signs and symptoms consistent with infection by the bacteria. Ten isolates were obtained from urine, sixteen from pus samples from deep wounds, thirteenfrom sputum and nine samples were obtained from blood.

\section{Isolation and Processing of Samples}

Freshwater and wastewater samples were serially diluted and $100 \mu \mathrm{L}$ of the diluted samples were plated on Cetrimide agar (Merck, Germany). Clinical samples were plated directly on the Cetrimide agar. Samples were incubated at $42^{\circ} \mathrm{C}$. Pseudomonas-like isolates were thereafter 


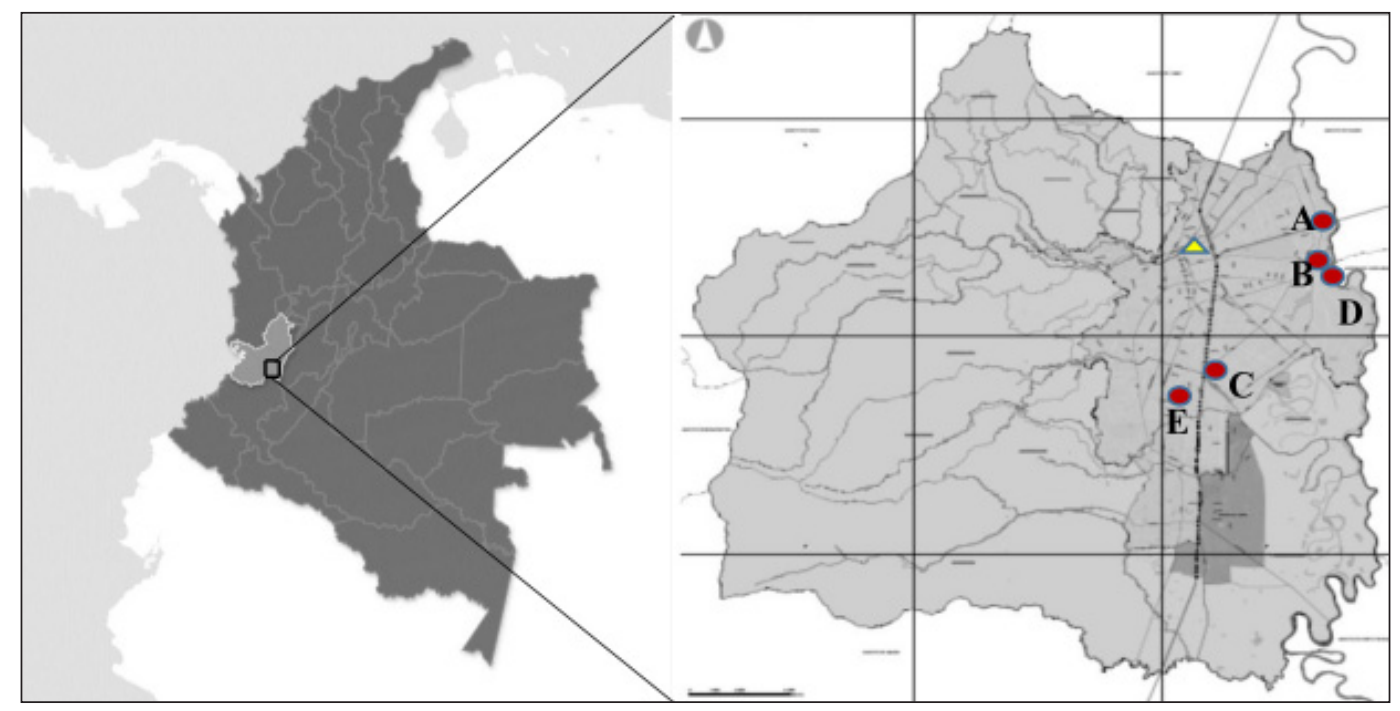

Figure 1. Geographical location of the sampling site.

(a) Department of Valle del Cauca, Colombia (b) City of Cali. (c). Red points show the sites where surface water samples were collected: Wastewater treatment plant "Cañaveralejo PTAR-C" (A), rainwater channel (B) near the wastewater treatment plant, Canal Intersector (CVC) Sur (C), water treatment plant "Puerto Mallarino" (D) and Melendez River (E), and the yellow triangle indicate the location of the hospital from which the clinical samples were obtained.

transferred into Nutrient agar (Oxoid Ltd., Hampshire, United Kingdom) plates and incubated overnight at $37^{\circ} \mathrm{C}$ and thereafter screened based on typical morphology, catalase and oxidase reactions. The purified isolates of $P$. aeruginosa were finally confirmed with a Vitek GNI+ system (bioMeriex Vitek Inc., Hazelwood, MO), which is a rapid and reliable identification method.

\section{DNA Isolation and Extraction}

DNA extraction was carried out from bacterial culture in LB (Luria-Bertani) broth, using the genomic DNA extraction kit (MOBIO Laboratories, QIAGEN).

The concentration of DNA in the samples was quantified by using a FOTO/Analyst ${ }^{\circledR}$ Investigator/FX Systems (FOTODYNE Incorporated).

\section{Identification of Isolates by Polymerase Chain Reaction (PCR)}

Confirmation of $P$. aeruginosa isolates was performed through DNAr 16S gene detection with Specific primers PA-GS-F (5'-TCAGTCACACTGGAACTGAG-3'), and
PA-GS-R (5'-GTAATTCCGAGGAACGCTTG$\left.3^{\prime}\right)$ to amplify a fragment of approximately $240 \mathrm{bp}$, according to the protocol established by Rolain et al., 2004. P. aeruginosa reference strain ATCC 27853 was used as positive control and a reaction mixture containing Nuclease free water as negative control. The amplified PCR products were analysed by gel electrophoresis in 1.2\% agarose gels stained with ethidium bromide (EtBr) $0.5 \mathrm{mg} / \mathrm{L}$, for $1 \mathrm{~h}$ at $100 \mathrm{~V}$ in $0.5 \times \mathrm{TAE}$ buffer (40 mM Tris-HCl, $20 \mathrm{mM}$ Na-acetate, 1 mM EDTA, pH 8.5).

\section{Determination of antibiotic resistance profiles}

Antibiotic resistance profiles were obtained from 220 isolates (84 environmental isolates obtained during the dry season, 88 isolated during the wet season and 48 clinical isolates). A standardized amount was inoculated (standard 0.5 of Mc Farland) and antimicrobial susceptibility testing was determined by disk diffusion method on Mueller-Hinton (MH) agar (Difco Laboratories, Detroit, MI, USA), using interpretative criteria of the Clinical and Laboratory 
Standard Institute (CLSI) (Wanyne, 2015). The following antimicrobials were used: Trimetroprim/Sulfametoxazol (SXT, 23.75 $\mu \mathrm{g}+1.25 \mu \mathrm{g}$ ), Gentamicin (GEN, $10 \mu \mathrm{g}$ ), Ciprofloxacin (CIP, $5 \mu \mathrm{g}$ ), Ceftazidime (CAZ, $30 \mu \mathrm{g}$ ), Cefoxitin (FOX, $30 \mu \mathrm{g}$ ), Cefotaxime (CTX, $30 \mu \mathrm{g}$ ), Meropenem (MEM, $10 \mu \mathrm{g}$ ), Piperacillin/Tazobactam (TZP, $40 \mu \mathrm{g}$ ), Cefixime (CFM, 5 ug) (Oxoid Ltd., Hampshire, United Kingdom). Intermediate susceptibility to each antibiotic was considered to be resistance. Quality control was carried out using standard strains of Escherichia coli (ATCC 25922), Pseudomonas aeruginosa (ATCC 27853).

According to the definitions proposed by Magiorakos et al. (2012), resistance to three or more antibiotic classes were defined as multidrug resistant $P$. aeruginosa (MDRPA).

\section{Polymerase Chain Reaction (PCR) to Detect bla Genes}

The extended-spectrum $\beta$-lactamases were identified by polymerase chain reaction with consensus primers targeting $b l a_{\mathrm{TEM}-1}$, $b l a_{\mathrm{CTX}-\mathrm{M}-9}, b l a_{\mathrm{PER}-1}, b l a_{\mathrm{OXA}-10}, b l a_{\mathrm{IMP}-1}, b l a_{\mathrm{VIM}-2}$ and $b l a_{\text {AMPc }}$ genes shown in Table 1.

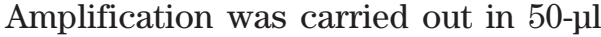
volumes with 5-10 ng (genomic DNA) reaction buffer, $1 \mathrm{U}$ of $\mathrm{Ta} q$ polymerase (Bioline, London, United Kingdom), $200 \mu \mathrm{M}$ each deoxynucleoside triphosphate, 1.5 or
2,5 $\mathrm{mM} \mathrm{MgCl} 2,10 \mathrm{pmol}$ of each primer, and $4 \mu \mathrm{l}$ of DNA as the template. PCR conditions generally were as follows: a hot start at $94^{\circ} \mathrm{C}$ for $5 \mathrm{~min}$; 35 cycles of $30 \mathrm{~s}$ at $94^{\circ} \mathrm{C}, 45 \mathrm{~s}$ at either $52^{\circ} \mathrm{C}\left(b l a_{\text {TEM-1 }}, b l a_{\text {PER-1 }}\right.$ and $\left.b l a_{\text {OXA-10 }}\right)$, $45 \mathrm{~s}$ at $51^{\circ} \mathrm{C}\left(b l a_{\text {CXT-M9 }}\right.$ and $\left.b l a_{\text {AMPc }}\right), 1 \mathrm{~min}$ at $51^{\circ} \mathrm{C}\left(b l a_{\mathrm{VIM}-2}, b l a_{\mathrm{IMP}-1}\right.$ and $\left.b l a_{\mathrm{KPC}-2}\right)$, and $60 \mathrm{~s}$ at $72^{\circ} \mathrm{C}$; and a final step of $10 \mathrm{~min}$ at $72^{\circ} \mathrm{C}$.

Five micro-liter of PCR products were analyzed in 1.1\% agarose (Sigma, USA) and the results were observed under UV light.

Single-strand conformation polymorphism (SSCP)- PCR for the analysis of $P$. aureginosa isolates

To define the SSCP profiles, the PCR amplification products of the $240 \mathrm{bp}$ fragment of rDNA16 of $P$. aeruginosa was subjected to a denaturing process by treating $5 \mu \mathrm{L}$ of denaturing buffer (5 mM EDTA, 0.05\% bromephenol blue, $0.05 \%$ xylencianol and $95 \%$ formamide) with $5 \mu \mathrm{L}$ of DNA amplified at $95^{\circ} \mathrm{C}$ for 10 minutes and perform electrophoresis on gels of $8.0 \%$ polyacrylamide in TBE buffer (0.09 M Tris-borate, 2 mM EDTA, $\mathrm{pH}$ 8.0).

\section{Statistical methods}

Differences in frequencies of antibiotypes and $\beta$-lactamases -genotypes among groups was evaluated using Chi-squared tests $(\chi 2)$ on contingency tables with a significance level of $\mathrm{P}<0.05$. Univariate analysis of

Table 1. Primers used in study

\begin{tabular}{|c|c|c|c|}
\hline Primer & Oligonucleotide sequence $\left(5^{\prime} \rightarrow 3\right)$ & Size (pb) & References \\
\hline$B l a_{\mathrm{KPC}-2}$ & $\begin{array}{l}\text { F-5'GGACACACCCATCCGTTA-3' } \\
\text { R-5'GCGGGCGTTATCACTGTATTG-3' }\end{array}$ & 956 & Correa et al., 2015 \\
\hline$b l a_{\mathrm{CTX}-\mathrm{M}-9}$ & $\begin{array}{l}\text { F-5'GTGACAAAGAGAGTGCAACGG-3' } \\
\text { R-5'TGCAACTTCATGTTATGCCG-3' }\end{array}$ & 856 & Shacheraghi et al., 2010 \\
\hline$b l a_{\mathrm{PER}-1}$ & $\begin{array}{l}\text { F-5'ATGAATGTCATTATAAAAGCT-3' } \\
\text { R-5'TTAATTTGG GCTTAGGG-3' }\end{array}$ & 927 & Nordman \& Naas, 1994 \\
\hline$b l a_{\text {OXA-10 }}$ & $\begin{array}{l}\text { F-5'TGAGCACCATAAGGCAACCA-3' } \\
\text { R-5'TTGGGCTAAATGGAAGCGTTT-3' }\end{array}$ & 311 & Kuo et al., 2010 \\
\hline$b l a_{\mathrm{IMP}-1}$ & $\begin{array}{l}\text { F-5'ATGAGCAAGTTATCCTTATTC-3' } \\
\text { R-5'GCTGCAACGACTTGTTAG-3' }\end{array}$ & 741 & Khosravi et al., 2008 \\
\hline$b l a_{\mathrm{VIM}-2}$ & $\begin{array}{l}\text { R-5'ATGATTCTCGCCGCTGAAGCC-3' } \\
\text { F-5'AAAGTTATGCCGCACTCACC-3' }\end{array}$ & 865 & Poirel et al., 2002 \\
\hline$B l a_{\mathrm{ampC}}$ & $\begin{array}{l}\text { F-5'GGTATGGCTGTGGGTGTTA-3' } \\
\text { R-5'TCCGAAACGGTTAGTTGAG-3' }\end{array}$ & 882 & Coudron et al., 2000 \\
\hline
\end{tabular}


variance was performed for inference on differences in average numbers of multi-drug resistance between $\beta$-lactamases genotypes. Analyses were performed in IBM SPSS Statistics version 23.0 (Inc, Chicago).

\section{RESULTS}

A total of 172 environmental isolates of $P$. aeruginosa were obtained from the sites: Wastewater treatment plant "Cañaveralejo PTAR-C" ( $n=14$ during the dry season; $n=20$ during the wet season), rainwater channel ( $\mathrm{n}=$ 8 during the dry season; $\mathrm{n}=9$ during the wet season) near the wastewater treatment plant, Canal Intersector (CVC) Sur ( $\mathrm{n}=29$ during the dry season; $n=17$ during the wet season), water treatment plant "Puerto Mallarino" ( $\mathrm{n}=13$ during the dry season; $\mathrm{n}=$ 10 during the wet season) and Melendez River ( $n=20$ during the dry season; $n=32$ during the wet season) and 48 clinical isolates during study time.

\section{Patterns of susceptibility of the isolates clinical and environmental}

Molecular identification of the $P$. aeruginosa was carried out by amplifying a specific fragment of DNAr 16S gene. A total 220 $P$. aeruginosa isolates were tested for drug susceptibility with a panel of eight antimicrobials, widely used in Colombian hospitals as antipseudomonal agents. The isolates analyzed showed different levels of resistance to ceftazidime, cefoxitin, cefotaxime, piperacillin/tazobactam and meropenem. All isolates of $P$. aeruginosa showed resistance to non- $\beta$-lactam agents, including trimetroprim/sulfamethoxazole, fluoroquinolones such as ciprofloxacin and aminoglycosides, such as gentamicin.

About 50\% of the 172 enviromental isolates were resistant to at least one of the antibiotics tested. Differences were found between the environmental isolates of $P$. aeruginosa resistant obtained in the dry and wet season. Isolates with resistance to cefoxitin, cefotaxime, piperacillin/ tazobactam and trimetroprim/Sulfamethoxazole were significantly more prevalent during the dry season $(91.7 \%$ each, $\mathrm{p}<0.05)$.
Cefoxitin-resistant isolates $(93.2 \%, \mathrm{p}<0.05)$ continued to be prevalent during the wet season.

Among the clinical isolates, a significant prevalence of cefoxitin was detected (65\%, $\mathrm{p}<0.05$ ).

Table 2 shows the number of isolates from $P$. aeruginosa with resistance to antibiotics in environmental and clinical samples. From this susceptibility analysis, five profiles or antibiotypes were determined among the $P$. aeruginosa isolates. Table 3 shows the antibiotic sensitivity and resistance profile for each antibiotype. We classified seventeen of these 220 isolates as wild-type (antibiotype 1), fifteen as resistant (antibiotype 2) and 188 as MDRPA (antibiotypes 3, 4 and 5).

Wild-type and resistant strains were present in the clinical isolates and only in the waters of the rainwater channel and the Melendez River, whereas MDRPA strains were found in $66.7 \%$ and $90.7 \%$ of the clinical and environmental isolates, respectively.

Additionally, it was observed that twenty one (12.2\%) of the enviromental isolates were classified as antibiotype 3 which include seven (41.2\%) isolates obtained from the rainwater channel, ten (21.7\%) isolated from "Canal Intersector (CVC) Sur" and four (17.4\%) isolated from the water treatment plant "Puerto Mallarino". Three isolates of $P$. aueruginosa obtained from pus from deep wounds shared this antibiotype.

The environmental isolates included in the antibiotype 4 were the most abundant (51.7\%) and these were found in all the sites sampled, except in the rain water channel, obtaining a greater number of them in the Melendez River (63.5\%). Some clinical isolates also presented this antibiotype (27.1\%), and were found in seven urine samples and six sputum samples.

The antibiotype 5 grouped the isolates with resistance to all the antibiotics evaluated in this study. This antibiotype was the most representative among the clinical isolates (33.3\%) and was found from sputum, deep wounds, urine and blood samples. In the environmental isolates, the largest number was determined in the wastewater treatment plant "Cañaveralejo PTAR-C" (50\%). 


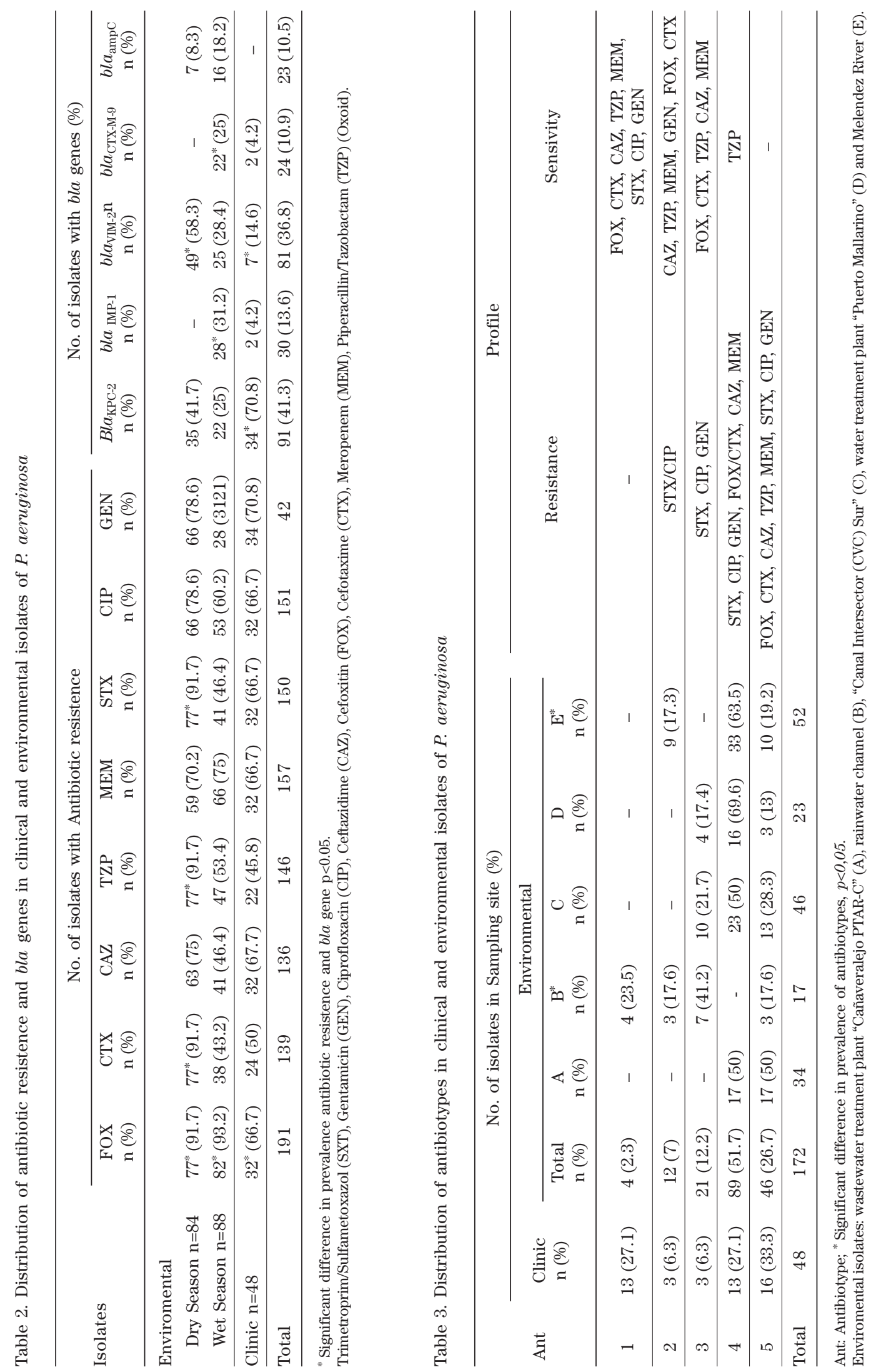




\section{Identification of Antibiotic Resistance bla Genes}

The screening for antibiotic resistance genes revealed the absence of $b l a_{\text {OXA-10 }}$ and $b l a_{\mathrm{PER}-1}$ genes as they were not detected in any of the $P$. aeruginosa isolates.

On the other hand, $b l a_{\mathrm{KPC}-2}$ gene was detected in the $70.8 \%$ of clinical isolates and $41.7 \%$ of environment isolates during dry season, but this decreased to $25 \%$ during wet season. Similarly, $b l a_{\mathrm{VIM}-2}$ gene was detected in the $58.3 \%$ of environment isolates during dry season and decreased to $28.4 \%$, although in clinical isolates they were only detected in $14.6 \%$ of them. The $b l a_{\text {CTX-M-9 }}$ and $b l a_{\text {IMP-1 }}$ genes were absent in the environmental isolates during the dry season and the $b l a_{\mathrm{ampC}}$ gene in clinical isolates (Table 2).

\section{Genetic characterization of $P$. aeruginosa isolates}

Figure 2 shows PCR-SSCP fingerprints generated for each of the $220 P$. aeruginosa isolates used in the antimicrobial testing, we detected three conformational patterns. Forty six enviromental isolates of the "Canal Intersector (CVC) Sur" showed identical banding patterns (bands of 330 and $320 \mathrm{bp}$ ) and were represented by the conformational pattern PCR-SSCP fingerprint I. A second group (composed of the bands of 280 and
$340 \mathrm{bp}$ ) represented by PCR-SSCP fingerprint II, included all clinical isolates and of the Melendez River isolates, nineteen isolates from the water treatment plant "Puerto Mallarino" and thirty four isolates from the wastewater treatment plant "Cañaveralejo PTAR-C".

Seventeen isolates from water treatment plant "Puerto Mallarino" constituted by two bands of 340 and $380 \mathrm{bp}$ (PCR-SSCP fingerprint III) clustered with four environmental isolates from rainwater channel (Table 4).

\section{DISCUSSION}

In this study, we analyzed 72 isolates of $P$. aeruginosa obtained from different types of clinical samples and artificial and natural waters of the city of Cali.

When comparing our sensitivity data with those available in Colombia and Latin America, the resistance rates of our $P$. aeruginosa isolates against piperacillin/ tazobactam, ceftazidime, meropenem, ciprofloxacin, and gentamicin were comparable with those reported in clinical isolates (Gales et al., 2012; Vanegas et al., 2014; Correa et al., 2015; Salvador et al., 2018). These classes of antibiotics are the

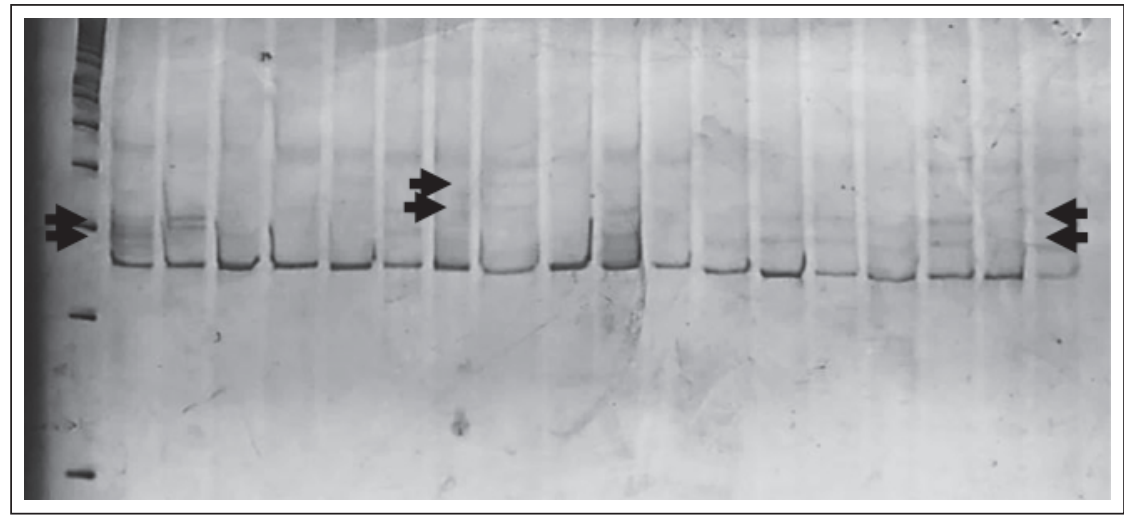

Figure 2. SSCP analysis of environmental and clinical isolates of $P$. aeruginosa. Lane 1: $100 \mathrm{bp}$ molecular weight marker, lanes 2, 3: isolates of the "Canal Intersector (CVC) Sur"; lane 4: 5, 11,12 isolates of the Meléndez River; lanes 6, 7, 9: isolates of water treatment plant "Puerto Mallarino"; lane 8: isolates of rainwater channel; lane 10: isolates of the treatment plant "Cañaveralejo PTAR-C; lane 13-19: clinic isolates. 


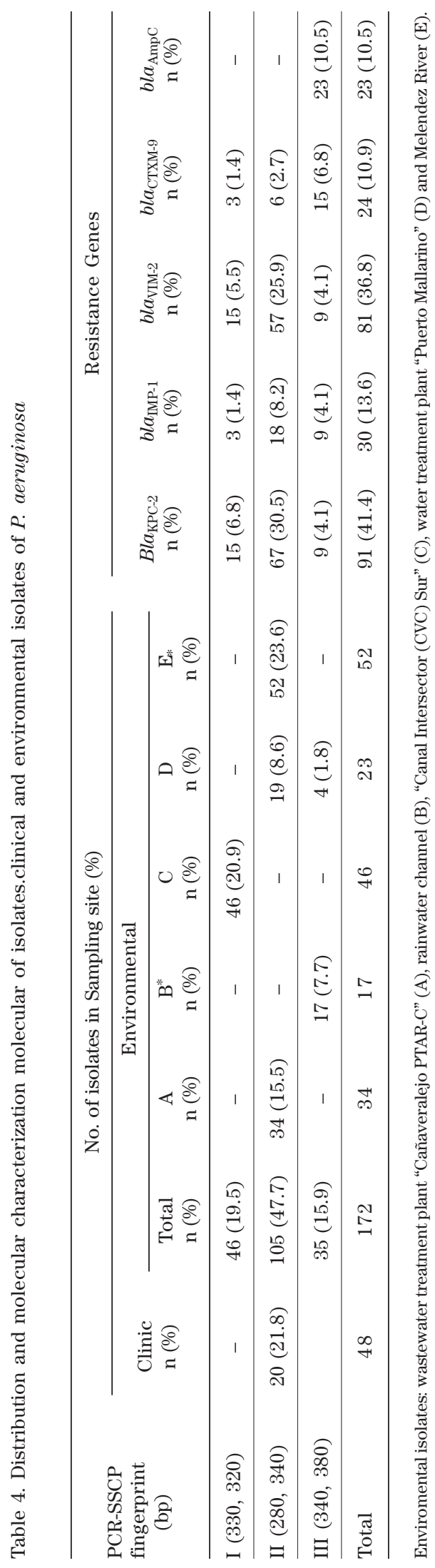


most used in $P$. aeruginosa isolates reflects the extensive and long-term use of these antimicrobial agents in our environment.

In our country, epidemiological data indicate a resistance to carbapenems in clinical isolates of $P$. aeruginosa greater than 50\% (Gales et al., 2012; Labarca et al., 2016; Salvador et al., 2018). In this study we found resistance to meropenem of $65 \%$ in clinical isolates and above $70 \%$ in those present in water systems, the rapid spread of carbapenemase-producing Gram-negative bacteria isolates has become a public health problem due to the few therapeutic options to treat the infections they cause.

Similarly, the epidemiological report of Pseudomonas spp. isolates obtained in river waters of the Republic of Congo and India and in sewage treatment plants in Switzerland indicated resistance to piperacillin and ceftazidime greater than $50 \%$, all isolates from water treatment plants in Switzerland were susceptible to carbapenems, while 15 and $33 \%$ of the isolates from Republic of Congo and India, respectively, were resistant to carbapenems (Devarajan et al., 2017).

According to these results, we can affirm that although the dynamics of resistance in $P$. aureginosa isolates varies between regions, there is a greater prevalence of resistant isolates in developing countries, such as Colombia.

Strains called wild-type (due to their sensitivity to all antibiotics evaluated in this study) were scarce. Instead, the prevalence of resistant strains was observed, especially MDRPA, which constituted $66.7 \%$ and $90.7 \%$ of clinical and environmental isolates, respectively.

Strains with the wild phenotype were preferentially isolated in clinical samples and only one isolate was detected in the rainwater channel (this channel also receives domestic water from the sector), while strains with MDRPA phenotype were more successful in colonizing all sampling areas in water systems, as well as the different clinical samples. However, in contrast to the results of the study conducted by Sivaraj et al. (2012), environmental isolates were highly resistance to the antibiotic when compared to the clinical isolates.

The results of this study show that the problem of multi-resistance of $P$. aeruginosa is not only limited to clinical isolates, in natural environments such as water systems, the seasonal distribution of $P$. aeruginosa did not reflect differences during the dry and wet season, the recovery of the bacteria being viable throughout the year, without being affected by the temperature changes or levels of waters system.

Our results coincide with previous studies that show that the bacteria remain stable in the water and that water treatment is not effective in eliminating the MDR bacteria (Sivaraj et al., 2012; Czekalski et al.,2014; Devarajan et al., 2016).

In the study conducted by Devarajan et al. (2017), multidrug resistant isolates were identified in all 3 sampling areas of India, Republic of Congo and Switzerland, concluding that water systems may play a role in preserving and dispersing MDRPA back to the human consumption via drinking water, fisheries or agricultural products using surface water for irrigation.

On the other hand, we found that all isolates belonging to antibiotics 3,4 and 5 (considered MDRPA) had the highest number of bla genes encoding metallo- $\beta$-lactamases.

Several studies indicate that MDRPA carries bla genes encoding MBL, located in gene cassettes within integrons, transposons or plasmids, together with genes encoding resistance to other antibiotic families (Lambert, 2002; Rodríguez et al., 2009). In our study, the isolates carrying $b l a_{\mathrm{KPC}-2}$ and $b l a_{\mathrm{VIM}-2}$ were $41.4 \%$ and $36.8 \%$, respectively in accordance with epidemiological data indicating that in Colombia, KPC-2 and VIM-2 carbapenemases are the most frequently detected among the clinical isolates of $P$. aeruginosa in Colombian hospitals (Crespo et al., 2004; Vanegas et al., 2014; Correa et al., 2015).

Among the environmental isolates, mostly harboring $b l a_{\mathrm{VIM}-2}$ and $b l a_{\mathrm{KPC}-2}$ significantly present during the dry season (58.3\% and $41.7 \%$, respectively) and continued to be detected during the wet season (28.4\% and 25\%, respectively). As suggested 
by Scotta et al. (2011), environmental bacteria represent a reservoir for the dissemination of clinically relevant $\beta$ lactamase genes.

In this study, we found that $b l a_{\mathrm{KPC}-2}$ was detected mainly among clinical isolates (70.8\%), in accordance with epidemiological data in Colombia, the clinical isolates of $P$. aeruginosa harbored bla $_{\mathrm{KPC}-2}$ are the main contributors of resistance in Colombian hospitals (Crespo et al., 2004; Vanegas et al., 2014; Correa et al., 2015).

Some reports indicate that ST111 and ST235 of $P$. aeruginosa are associated with the dissemination $b l a_{\mathrm{VIM}-2}$ and $b l a_{\mathrm{KPC}-2}$ in Colombia (Correa et al., 2015).

The presence of MDRPA isolates carrying bla genes in water systems may be related to uncontrolled elimination in the environment of the chemicals and antibiotics that are often used as $\beta$-lactams, which creates a selective pressure on these microorganisms that leads to multiple resistance to drugs with transfer of resistance genes from pathogenic to non-pathogenic strains or vice versa in the environment.

Using the PCR-SSCP analysis, our data shows that there is a great adaptability of $P$. aeruginosa isolates. There are isolates clearly adapted to the aquatic environment (PCR-SSCP fingerprint I and III). Environmental isolates from "Canal Intersector (CVC) Sur" were more closely related among themselves (PCR-SSCP fingerprint I). This channel collects domestic and industrial waste from the southeast of the city and the waters of the Cañaveralejo River.

However, the largest number of isolates were grouped in PCR-SSCP fingerprint II, clinical isolates and environmental isolates from the surface waters of the Melendez River, among others were similar. In addition, the isolates of this group had the highest number of bla genes, especially bla $a_{\mathrm{VIM}-2}$ genes. A large number of environmental isolates originating from clinical isolates can remain viable throughout the year in water systems representing a risk, due to their propagation capacity, stability in different environments and resistance mediated by $\beta$-lactamases, including carbapenemases such as VIM-2 and KPC-2.
The results of the PCR-SSCP analyzes are consistent with the results of Finnan $e t$ $a l$. which show that $P$. aeruginosa strains recovered from clinical or environmental sources have a highly conserved genome, that allows to inhabit the widest possible range of environments and confers the ability to cause human infections after relatively infrequent encounters (Finnan et al., 2004).

On the other hand, it can be seen that isolates with the $b l a_{\mathrm{kpc}-2}, b l a_{\mathrm{CTX}-\mathrm{M}-9}, b l a_{\mathrm{IMP}-1}$ and $b l a_{\mathrm{VIM}-2}$ genes are found in the three types PCR-SSCP fingerprint, a fact that suggests that the resistance phenotype to $\beta$-lactams is the result of several transmission events, suggesting a complex transmission dynamic between hospital and environmental isolates.

As suggested by Wolfgang et al. (2003), the genome of $P$. aeruginosa is a dynamic entity in which horizontal gene transfer and recombination, together with gene loss, are a driving force in genetic diversity and play an important role in the evolution of this species. Through this mechanism, a conserved genome can have variability in virulence phenotypes and resistance to antibiotics.

We show here that $P$. aeruginosa is ubiquitous in the city's artificial and natural water systems and that antibiotic-resistant (and, in particular, MDRPA) strains that are released from hospitals into the environment show great ecological efficacy when colonizing and remain for several periods in the city's water systems, especially strains that harboring $b l a_{\mathrm{VIM}}$ and $b l a_{\mathrm{KPC}-2}$.

The appearance of MDRPA in natural and artificial waters is of great concern due to the possible transfer of resistance genes from non-pathogenic strains to pathogenic strains or vice versa in the environment.

Acknowledgments. The authors thank the General Research Direction (DGI) at Universidad Santiago de Cali for the economic support to conduct this study; gratitude is also expressed to CEIS for the support granted. 


\section{REFERENCES}

Akinpelu, A.T., Akinloye, O.M., Olufemi, B., Degoke, A.E.A. \& Olayinka, S. (2014). Antibiotic resistant pattern of isolated bacteria fom Obere River in onle-Igbon, Oyo State. Nigeria. African Journal of Microbiology Research 8: 1318-1321.

Allen, J.P., Ozer, E.A. \& Hauser, A.R. (2014). Different paths to pathogenesis. Trends in Microbiology 22: 168-169.

Baquero, F., Martínez, J.L. \& Cantón, R. (2008). Antibiotics and antibiotic resistance in water environments. Current Opinion in Biotechnology 19: 260-5,

Breathnach, A.S., Cubbon, M.D., Karunaharan, R.N., Pope, C.F. \& Planche, T.D. (2012). Multidrug- resistant Pseudomonas aeruginosa outbreaks in two hospitals: association with contaminated hospital waste-water systems. Journal of Hospital Infection 82: 19-24.

Correa, A., Del Campo, R., Perenguez, M., Blanco, V.M., Rodríguez-Baños, M., Perez, F., Maya, J.J., Rojas, L., Cantón, R., Arias, C.A. \& Villegas, M.V. (2015). Dissemination of high-risk clones of extensively drug-resistant Pseudomonas aeruginosa in Colombia. Antimicrobial Agents and Chemotherapy 59: 24212425.

Cortes, J.A., Leal, A.L., Montañez, A.M., Buitrago, G., Castillo, J.S. \& Guzman, L. (2013). Frequency of microorganisms isolated in patients with bacteremia in intensive care units in Colombia and their resistance profiles. Brazilian Journal of Infectious Diseases 17: 34652 ,

Coudron, P.E., Moland, E.S. \& Thomson, K.S. (2000). Occurrence and detection of AmpC beta- lactamases among Escherichia coli, Klebsiella pneumoniae, and Proteus mirabilis isolates at a veterans medical center. Journal of Clinical Microbiology 38: 1791-6.

Crespo, M.P., Woodford, N., Sinclair, A., Kaufmann, M.E., Turton, J., Lover, J.G., Velez, J.D., Castañeda, C.R., Recalde, M., \& Livermore, D.M. (2004). Outbreak of carbapenem-resistant Pseudomonas aeruginosa producing VIM-8, a novel metallo- $\beta$-lactamase, in a tertiary care center in Cali, Colombia. Journal of Clinical Microbiology 42: 5094-10. doi: 10.1128/JCM.42.11.5094-5101.

Czekalski, N., Gascon-Diez, E. \& Burgmann, H. (2014). Wastewater as a point source of antibiotic-resistance genes in the sediment of a freshwater lake. ISME Journal 8: 1381e1390,

Decker, B.K. \& Palmore, T.N. (2013). The role of water in healthcare-associated infections. Current Opinion in Infectious Diseases 26: 345-51.

Devarajan, N., Laffite, A., Mulaji, C.K., Otamonga, J.P., Mpiana, P.T., Mubedi, J.I., Prabakar, K., Ibelings, B.W. \& Pote, J. (2016). Occurrence of antibiotic resistance genes and bacterial markers in a tropical river receiving hospital and urban wastewaters. PLoS One 11 https:// doi.org/10.1371/journal.pone.0149211

Devarajan, N., Thilo, K., Periyasamy, S., Delden, C., Mulaji, C.K., Mpiana, P.T. \& Pote, B.J. (2017). Antibiotic resistant Pseudomonas spp. in the aquatic environment: A prevalence study under tropical and temperate climate conditions. Water Research 115: 256-265, doi: 10.1016/j.watres.2017.02.058

Finnan, S., Morrissey, J.P., O'Gara, F. \& Boyd, E.F. (2004). Genome Diversity of Pseudomonas aeruginosa Isolates from Cystic Fibrosis Patients and the Hospital Environment. Journal of Clinical Microbiology 42: 5783-5792, doi: 10.1128/JCM.42.12.5783-5792.2004.

Gales, A.C., Castanheira, M., Jones, R.N. \& Sader, S. (2012). Antimicrobial resistance among Gram-negative bacilli isolated from Latin America: results from SENTRY Antimicrobial Surveillance Program (Latin America, 2008-2010). Diagnostic Microbiology and Infectious Disease 73: 354-60,

Giamarellou, H. (2002). Prescribing guidelines for severe Pseudomonas infections. Journal Antimicrobial Chemotherapy 49: 229-33.

Inglis, T.J., Benson, K.A., O’Reilly, L., Bradbury, R., Hodge, M., Speers, D. \& Heath, C.H. (2010). Emergence of multi-resistant Pseudomonas aeruginosa in a Western 
Australian hospital. Journal of Hospital Infection 76: 60-5. doi: 10.1016/j.jhin. 2010.01.026.

Jeannot, K., Fournier, D., Müller, E., Cholley, P. \& Plésiat, P. (2013). Clonal Dissemination of Pseudomonas aeruginosa isolates producing extended-spectrum $\beta$-Lactamase SHV-2a. Journal of Clinical Microbiology 51: 673-5.

Khosravi, A.D. \& Mihani, F. (2008). Detection of metallo-beta-lactamase-producing Pseudomonas aeruginosa strains isolated from burn patients in Ahwaz, Iran. Diagnostic Microbiology and Infectious Disease 60: 125-8.

Kuo, H., Yang, C., Lin, M., Cheng, W., Tiene, N. \& Liou, M. (2010). Distribution of $b l a_{\mathrm{OXA}^{-}}$ carrying imipenem-resistant Acinetobacter spp. in 3 hospitals in Taiwan. Diagnostic Microbiology and Infectious Disease 66: 195-199.

Labarca, J.A., Salles, M.J., Seas, C. \& Guzmán-Blanco, M. (2016). Carbapenem resistance in Pseudomonas aeruginosa and Acinetobacter baumannii in the nosocomial setting in Latin America. Critical Reviews in Microbiology 42: 276-92, doi: 10.3109/1040841X.2014. 940494.

Lalancette, C., Charron, D., Laferrière, C., Dolcé, P., Déziel, E., Prévost, M. \& Bédard, E. (2017). Hospital Drains as Reservoirs of Pseudomonas aeruginosa: MultipleLocus Variable-Number of Tandem Repeats Analysis Genotypes Recovered from Faucets, Sink Surfaces and Patients. Pathogens 6: 36-39, doi: 10. 3390/pathogens6030036.

Lambert, P. (2002). Mechanism of antibiotic resistance in Pseudomonas aeruginosa. Journal of the Royal Society of Medicine 95: S22-6.

Luna, R.A., Millecker, L., Webb, C.R., Mason, S.K., Whaley, E.M., Starke, J.R., Hiatt, P.W. \& Versalovica, J. (2013). Molecular epidemiological surveillance of multidrug-resistant Pseudomonas aeruginosa isolates in a pediatric population of patients with cystic fibrosis for infection with the houston-1 strain. Journal of Clinical Microbiology 51: 1237-40. doi: 10.1128/JCM.02157-12
Mabilat, C. \& Courvalin, P. (1990). Development of oligotyping for characterization and molecular epidemiology of TEM $\beta$-lactamases in members of the family Enterobacteriaceae. Antimicrobial Agents and Chemotherapy 34: 2210-6.

Magiorakos, A.P., Srinivasan, A., Carey, R.B., Carmeli, Y., Falagas, M.E., Giske, C.G., Harbarth, S., Hindler, J.F., Kahlmeter, G., Olsson-Liljequist, B., Paterson, D.L., Rice, L.B., Stelling, J., Struelens, M.J., Atopoulos, A.V., Eber, J.T.W. \& Monnet, D.L. (2012). Multidrug-resistant, extensively drug-resistant and pandrugresistant bacteria: an international expert proposal for interim standard definitions for acquired resistance. Clinical Microbiology and Infection 18: 268-281.

Nordman, P. \& Naas, T. (1994). Sequence analysis of PER-1 extended-spectrum $\beta$-lactamases from Pseudomonas aeruginosa and comparison with class A $\beta$-lactamases. Antimicrobial Agents and Chemotherapy 38: 104-14.

Poirel, L., Naas, T., Nicolas, D., Collet, L., Bellais, S., Cavallo, J.D. \& Nordmann, P. (2000). Characterization of VIM-2, a carbapenem-hydrolyzing metallolactamase, and its plasmid- and integronborne gene from a Pseudomonas aeruginosa clinical isolate in France. Antimicrobial Agents and Chemotherapy 44: 891-897.

Rodríguez-Martínez, J.M., Poirel, L. \& Nordmann, P. (2009). Molecular epidemiology and mechanisms of carbapenem resistance in Pseudomonas aeruginosa. Antimicrobial Agents and Chemotherapy 53: 4783-4788.

Rolain, J.M., Mallet, M.N., Fournier, P.E. \& Raoult, D. (2004). Real-time PCR for universal antibiotic susceptibility testing. Journal Antimicrobial Chemotherapy 54: 538-541.

Salvador, G., García, L.R. \& Gonzales, E. (2018). Characterization of metallo- $\beta$ lactamase in clinical isolates of Pseudomonas aeruginosa retrieved from patients hospitalized in the Central Military Hospital. Revista Peruana de Medicina Experimental y Salud Pública 
35: 636-641, doi: 10.17843/rpmesp.2018. 354.3755 .

Scotta, C., Juan, C., Cabot, G., Oliver, A., Alucat, J.L., Bennasar, A. \& Albertí, S. (2011). Environmental microbiota represents a natural reservoir for dissemination of clinically relevant metallo- $\beta$ lactamases. Antimicrobial Agents and Chemotherapy 55: 5376-5379. doi: 10. 1128/AAC.00716-11

Shacheraghi, F., Shakibaie, M.R. \& Noveiri, H. (2010). Molecular Identification of ESBL genes $b l a_{\mathrm{GES}-1}, b l a_{\mathrm{VEB}-1}, b l a_{\mathrm{CTX}-\mathrm{M}}$ $b l a_{\text {OXA-1 }}, b l a_{\text {OXA- } 4}, b l a_{\text {OXA-10 }}$ and $b l a_{\text {PER-1 }}$ in Pseudomonas aeruginosa strains isolated from burn patients by PCR, RFLP and sequencing techniques. International Journal of Biology and Life Science 3: 138-42.

Sivaraj, S., Murugesan, P., Muthuvelu, S., Purusothaman, S. \& Silambarasan, A. (2012). Comparative study of Pseudomonas aeruginosa isolate recovered from clinical and environmental samples against antibiotics. International Journal of Pharmacy and Pharmaceutical Sciences 4: 103-107.

Vanegas, J.M., Cienfuegos, A.V., Ocampo, A.M., López, L., del Corral, H., Roncancio, G., Sierra, P., Echeverri-Toro, L., Ospina, S., Robledo, N.C., Restrepo, A. \& Jiménez, N. (2014). Similar Frequencies of Pseudomonas aeruginosa Isolates Producing KPC and VIM Carbapenemases in Diverse Genetic Clones at Tertiary-Care Hospitals in Medellín, Colombia. Journal of Clinical Microbiology 52: 3978-3986 doi: 10.1128/ JCM.01879-14
Vaz-Moreira, I., Nunes, O.C. \& Manaia, C.M. (2012). Diversity and antibiotic resistance in Pseudomonas spp. from drinking water. Science of the Total Environment 426: $366-374$.

Wanyne, P.I.C.a.l.s.i. (2015). Clinical and Laboratory Standards Institute. Performance standards for antimicrobial susceptibility testing; $25^{\text {th }}$ informational supplement. CLSI M100-S25.

Wolfgang, M.C., Kulasekara, B.R., Liang, X., Boyd, D., Wu, K., Qing, Y., Miyada, C.G. \& Lory, S. (2003). Conservation of genome content and virulence determinants among clinical and environmental isolates of Pseudomonas aeruginosa. Proceedings of the National Academy of Sciences 100: 8484-8489. doi:10.1073. pnas. 0832438100

Wu, D.Q., Li, Y. \& Xu, Y. (2012). Comparative analysis of temperature-dependent transcriptome of Pseudomonas aeruginosa strains from rhizosphere and human habitats. Applied Microbiology and Biotechnology 96: 1007-1019.

Yang, C.M., Lin, M.F., Liao, P.C., Yeh, H.W., Chang, B.V., Tang, T.K., Cheng, C., Sung, C.H. \& Liou, M.L. (2009). Comparison of antimicrobial resistance patterns between clinical and sewage isolates in a regional hospital in Taiwan. Letters in Applied Microbiology 48: 560-565. https://doi.org/10.1111/j.1472-765X. 2009.02572.x 